\title{
Adhesion Improvement between RAP and Emulsified Asphalt by Modifying the Surface Characteristics of RAP
}

\author{
Zhenjun Wang $\mathbb{D},{ }^{1,2}$ Pei Wang, ${ }^{1}$ Haoyan Guo, ${ }^{1}$ Xiaofeng Wang $\mathbb{D},{ }^{3}$ and Gang Li $\mathbb{D}^{4}$ \\ ${ }^{1}$ School of Materials Science and Engineering, Chang'an University, Xi'an 710061, China \\ ${ }^{2}$ State Key Lab High Performance Civil Engineering Materials, Nanjing 211103, China \\ ${ }^{3}$ Henan Provincial Communications Planning \& Design Institute, Zhengzhou 450052, China \\ ${ }^{4}$ College of Water Conservancy and Architectural Engineering, Shihezi University, Shihezi 832000, China \\ Correspondence should be addressed to Zhenjun Wang; zjwang@chd.edu.cn and Xiaofeng Wang; wangxf0351@sina.com
}

Received 27 December 2019; Revised 8 February 2020; Accepted 2 March 2020; Published 22 April 2020

Guest Editor: Andrea Graziani

Copyright ( 2020 Zhenjun Wang et al. This is an open access article distributed under the Creative Commons Attribution License, which permits unrestricted use, distribution, and reproduction in any medium, provided the original work is properly cited.

\begin{abstract}
Recycled asphalt pavement (RAP) can be used in highway engineering again by cold recycled technology. Due to the aged asphalt on the surface of RAP, some problems such as poor adhesion between emulsified asphalt and RAP and the low properties of emulsified asphalt recycling mixture are easy to occur. This work aims at analyzing the aging degree of asphalt from RAP surface and improving the poor adhesion between RAP and emulsified asphalt by modifying the surface characteristics of RAP. In this work, a new device was designed to delaminate off the asphalt on the surface of RAP. The aging degree of asphalt at different layers was studied then by physical properties and molecular weight distribution. Slurry of hydrated lime $\left(\mathrm{Ca}(\mathrm{OH})_{2}\right)(\mathrm{S}-\mathrm{Ca})$ and slurry of silane coupling agent $(\mathrm{SCA})$ modified $\mathrm{Ca}(\mathrm{OH})_{2}(\mathrm{~S}-\mathrm{Si}-\mathrm{Ca})$ were used to modify the asphalt on the surface of RAP, respectively. The adhesion between emulsified asphalt and RAP was studied by contact angle and boiling method. Results show that the asphalt on the RAP surface can be successfully stripped into four layers through the self-designed RAP delaminating and stripping device. The aging degree of asphalt wrapped around the surface of the RAP showed a tendency to be gradually severe from outside to inside. However, asphalt at the innermost layer (L4) shows abnormal situation due to the fact that the light components are absorbed by the aggregate. In addition, reasonable dosage of SCA is determined as $3.0 \%$ in $\mathrm{Ca}(\mathrm{OH})_{2}$ powder mass. Both S-Ca and $\mathrm{S}$-Si-Ca can effectively reduce the contact angle and thus improve the adhesion between emulsified asphalt and RAP. Moreover, $\mathrm{S}$-Si-Ca possesses the most obvious modification effect attributed to the formation of asphalt-SCA-Ca $(\mathrm{OH})_{2}$ structure.
\end{abstract}

\section{Introduction}

During the service of asphalt pavement, aging can inevitably occur due to the combined effects of heat, oxygen, sunlight, and water. The utilization of recycled asphalt pavement (RAP) in the cold recycling process of asphalt pavement possesses the dual benefits of saving energy and protecting the environment $[1,2]$. However, the application of RAP in asphalt mixture is highly limited due to the presence of the aged asphalt on the RAP surface $[3,4]$, which can reduce the properties of cold recycled asphalt mixture.

The surface aging degree of RAP is usually different from that of the RAP internal [5-7]. It was found that there was a big difference between the recycled asphalt and the asphalt because the mineral powder can absorb certain components in the asphalt [8]. The penetration and ductility of the extracted aged asphalt decreased while the softening point increased with the increase of the service life of RAP [9]. Although the aging behavior of asphalt on the RAP surface has been confirmed, the aging degree of different layers of asphalt has not been distinguished.

The poor adhesion of the RAP-new asphalt interface has been an important factor restricting the development of high-performance cold recycled mixture [10]. Some modification methods have been used for improving the properties of cold recycled mixture [11-14]. It is effective to modify asphalt mixture with a reactive powder [15-17]. Hydrated lime can significantly reduce the polarity 
difference between asphalt and aggregate and improve the surface free energy of asphalt and the adhesion between asphalt and aggregate [18]. The addition of fly ash can improve the mechanical property and durability of cold recycled asphalt mixture [19]. Cement can improve the early strength and water damage resistance of asphalt emulsion mixture [20]. In addition, the adhesion between asphalt and aggregate depends largely on conditions of aggregate minerals [21]; $\mathrm{SiO}_{2}$ in aggregate can improve the adhesion between asphalt and aggregate due to physical adsorption [22]. For other modifiers, silane and amine can improve the RAP aggregate-new asphalt interface property [23]. Bio-oil can improve the high-temperature performance of RAP mixture in a humid environment [24].

However, most of the above studies are qualitative evaluation and there are few methods to evaluate quantitatively the modification effect of asphalt on the RAP surface, and the modification effect of aged asphalt on the RAP surface is still poor. Therefore, it is of great value to put forward one technique to improve the surface properties of RAP and its adhesion to emulsified asphalt. In this work, the characteristics analyses of aged asphalt on the RAP surface were conducted before utilizing RAP to determine the aging degree and select three appropriate modifiers to improve the surface characteristics of aged asphalt, which is expected to obtain the best RAP-new asphalt adhesion and optimize various properties of recycled asphalt mixtures.

\section{Materials and Experimental}

2.1. Materials. The physical and chemical properties of the asphalt selected in this paper are shown in Table 1. Emulsified asphalt was prepared using a cationic emulsifier and its properties are shown in Table 2. The main properties of the selected modifiers $\left(\mathrm{Ca}(\mathrm{OH})_{2}\right.$ and $\mathrm{KH}-550$ SCA) are shown in Table 3 and Table 4, respectively. The properties of the solvent trichloroethylene (TCE) are shown in Table 5.

2.2. Stripping of Asphalt at Different Layers of RAP Surface. In order to evaluate the performance of asphalt at different layers of RAP, a kind of self-designed device was developed in this work, based on the Abson method (T 0726-2011) in the Standard Test Methods of Bitumen and Bituminous Mixtures for Highway Engineering in China (JTG E20-2011), whose specific steps can be consulted from reference [25]. The device can effectively strip asphalt on the surface of RAP. In view of the rapid dissolving properties of asphalt in TCE, TCE was used as a solvent in this work to wash down the asphalt on the RAP surface layer by layer. As shown in Figure 1, the asphalt on the RAP surface was divided into four layers from outside to inside and labeled as layer 1, L1; layer 2, L2; layer 3, L3; and layer 4, L4, respectively.

The schematic diagram of the device for stripping asphalt is shown in Figure 2. $100 \mathrm{~g}$ of RAP with a particle size of $13.2 \mathrm{~mm}-19 \mathrm{~mm}$ was selected and rinsed with water to remove surface dust and sand as much as possible firstly. The washed RAP was placed into the device shown in Figure 2 after drying naturally. The RAP was then rinsed with a fixed volume of TCE. After the TCE completely flowed out, the dissolved asphalt solution was collected, impurities such as mineral powder were removed, and asphalt sample was finally obtained after evaporation of TCE. The obtained asphalt samples were marked and labeled as L1, L2, L3, and L4, respectively (as shown in Figure 3).

2.3. Preparation of Modified Slurries. In this work, SCA solution (S-Si), S-Ca, and S-Si-Ca were used to improve the surface characteristics of RAP and increase its adhesion to emulsified asphalt. The three modifiers were prepared as follows:

(1) In order to accelerate the ionization and dispersion of SCA in the solution, a certain concentration of the solution was prepared firstly and the formulation ratio of the solution is shown in Table 6. The $\mathrm{pH}$ value of the solution was adjusted to 4 by acetic acid. After the SCA was hydrolyzed in the solution at room temperature for $20 \mathrm{~min}$, SCA solution (S-Si) was obtained.

(2) The hydrated lime powder and water were prepared in a mass ratio of $0.3: 100$ and placed in a beaker, and then, the beaker was placed on a magnetic stirrer and stirred for 30 minutes at $30^{\circ} \mathrm{C}$. Finally, slurry of hydrated lime (S-Ca) was obtained.

(3) The hydrated lime possesses highly polar property and it is difficult to adhere to asphalt under normal temperature conditions. Therefore, $\mathrm{Ca}(\mathrm{OH})_{2}$ was modified in this work. After the prepared $\mathrm{S}$-Si was mixed with S-Ca, the slurry was stirred at $30^{\circ} \mathrm{C}$ for $20 \mathrm{~min}$ to obtain slurry of silane coupling agent modified $\mathrm{Ca}(\mathrm{OH})_{2}$ (S-Si-Ca). In this work, $1 \%, 2 \%$, $3 \%, 4 \%$, and $5 \% \mathrm{SCA}\left(\mathrm{Ca}(\mathrm{OH})_{2}\right.$ powder weight $)$ were used to prepare $\mathrm{S}-\mathrm{Si}-\mathrm{Ca}$.

\subsection{Experiment Methods}

2.4.1. Physical Property Tests. The physical properties of asphalt at different layers were tested according to the Standard Test Methods of Bitumen and Bituminous Mixtures for Highway Engineering in China (JTG E20-2011), which includes softening point, penetration at $25^{\circ} \mathrm{C}$, and ductility at $25^{\circ} \mathrm{C}$. To ensure the reliability of the test data, three samples were prepared and tested for each of the three tests and the average value was finally adopted as the test result.

2.4.2. Gel Permeation Chromatography (GPC). GPC is a very accurate and efficient method for classifying polymers according to the molecular weight. In this work, polystyrene with known relative molecular mass was used as a monodisperse standard for direct correction; a standard curve was established and different layers of asphalt were measured and analyzed according to the standard curve. The temperature of the column was set to $25^{\circ} \mathrm{C}$; the mobile phase was tetrahydrofuran; the flow rate was $1.0 \mathrm{~mL} / \mathrm{min}$; and the concentration of the sample solution was $2.0 \mathrm{mg} / \mathrm{ml}$. A 
TABLe 1: Physical and chemical properties of original asphalt.

\begin{tabular}{ccc}
\hline Properties & Test results & Specification values \\
\hline Softening point $\left({ }^{\circ} \mathrm{C}\right)$ & 48.0 & $\geq 46$ \\
Penetration $\left(25^{\circ} \mathrm{C}, 100 \mathrm{~g}, 5 \mathrm{~s}\right)(0.1 \mathrm{~mm})$ & 71.2 & $60-80$ \\
Ductility $\left(15^{\circ} \mathrm{C}, 5^{\circ} \mathrm{cm} / \mathrm{min}\right)(\mathrm{cm})$ & $\geq 100$ & $\geq 100$ \\
Density $\left(15^{\circ} \mathrm{C}\right)\left(\mathrm{g} / \mathrm{m}^{3}\right)$ & 1.029 & - \\
Mass loss $\%)$ & 0.24 & $-0.8-0.8$ \\
RTFOT, penetration ratio $\left(25^{\circ} \mathrm{C}\right)(\%)$ & 65.9 & $\geq 61$ \\
Ductility $\left(15^{\circ} \mathrm{C}, 5 \mathrm{~cm} / \mathrm{min}\right)(\mathrm{cm})$ & 23.9 & $\geq 15$ \\
\hline
\end{tabular}

TABle 2: Properties of emulsified asphalt.

\begin{tabular}{lccc}
\hline & Properties & Test results & Specification values \\
\hline \multirow{2}{*}{ Evaporation residue } & Residue content $(\%)$ & 60.1 & $\geq 55$ \\
& Penetration $\left(25^{\circ} \mathrm{C}, 100 \mathrm{~g}, 5 \mathrm{~s}\right)(0.1 \mathrm{~mm})$ & 77.1 & $50-300$ \\
\multirow{2}{*}{ Storage stability $\left(\%, 25^{\circ} \mathrm{C}\right)$} & Ductility $\left(15^{\circ} \mathrm{C}, 5 \mathrm{~cm} / \mathrm{min}\right)(\mathrm{cm})$ & 49.8 & $\geq 40$ \\
& $1 \mathrm{~d}$ & 0.4 & $<.5$ \\
\hline
\end{tabular}

TABLE 3: Composition of hydrated lime.

\begin{tabular}{lccccc}
\hline Composition (\%) & $\mathrm{Ca}(\mathrm{OH})_{2}$ & Chloride & Sulfate & Magnesium salt & Iron element \\
\hline Mass fraction (\%) & $\geq 95.05$ & 0.01 & 0.2 & 0.2 & 0.01 \\
\hline
\end{tabular}

TABle 4: Properties of silane coupling agent.

\begin{tabular}{lccc}
\hline Properties & Chromatographic purity $(\%)$ & Density $\left(25^{\circ} \mathrm{C}\right)\left(\mathrm{g} / \mathrm{cm}^{3}\right)$ & Refractive index $\left(25^{\circ} \mathrm{C}\right)(\mathrm{m} / \mathrm{s})$ \\
\hline Test results & 98.1 & 0.944 & 1.419 \\
\hline
\end{tabular}

TABle 5: Properties of trichloroethylene (TCE).

\begin{tabular}{lccccc}
\hline Properties & Exterior & Density $\left(\mathrm{g} / \mathrm{cm}^{3}\right)$ & Boiling point $\left({ }^{\circ} \mathrm{C}\right)$ & Melting point $\left({ }^{\circ} \mathrm{C}\right)$ & Molecular weight \\
\hline Test results & Colorless & 1.460 & 87.4 & -87.0 & 131.39 \\
\hline
\end{tabular}

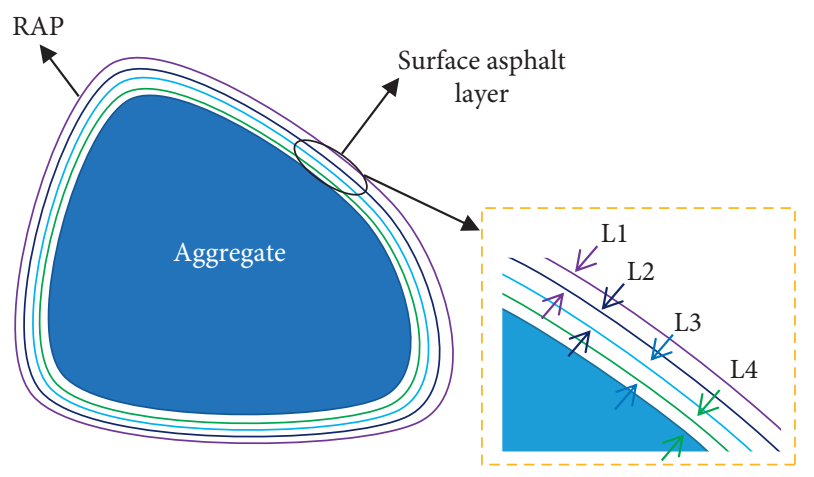

FIGURE 1: Schematic diagram of asphalt layers on the RAP surface.

normal GPC curve of the asphalt sample is shown in Figure 4.

Asphalt aging is the aggregation of small molecules to macromolecules. The higher the LMC, the more severe the aging of asphalt. The aging degree of asphalt at each layer can

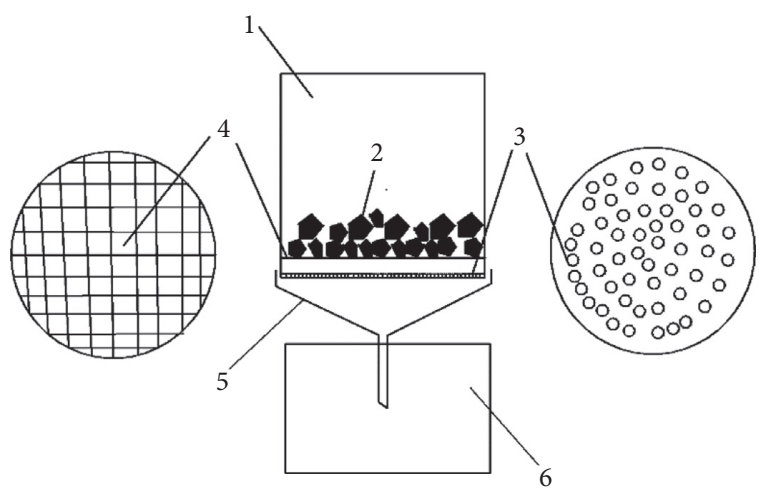

FIGURE 2: Schematic diagram of the device for stripping asphalt. (1) Container; (2) RAP; (3) chassis; (4) net-shaped support; (5) receiving funnel; (6) solution collecting device.

be evaluated by quantitatively calculating the ratio of large molecular content (LMC). The ratio of LMC to the entire molecular weight is used to quantitatively evaluate the aging degree of asphalt [25]. The LMC can be calculated according to the following equation: 


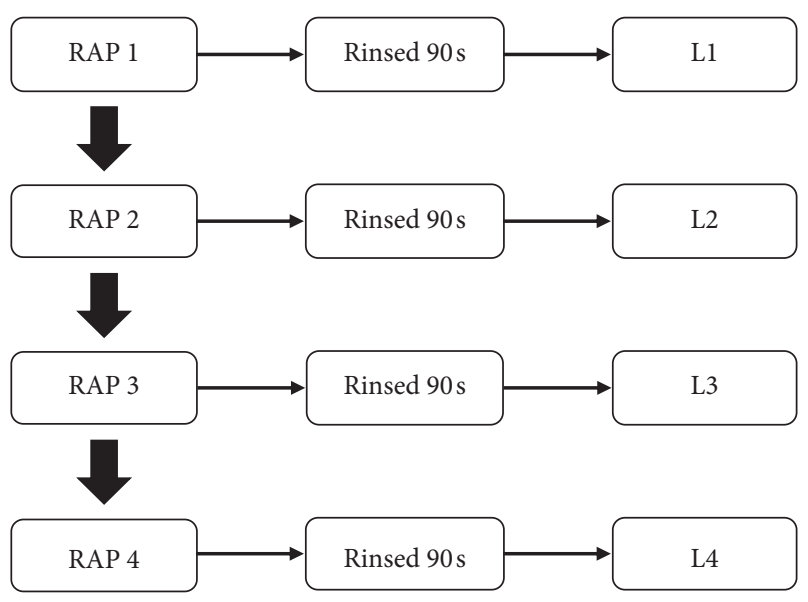

FIgURE 3: Schematic diagram of the RAP rinsing process.

TABLE 6: Formulation ratio of SCA solution.

\begin{tabular}{lccc}
\hline Composition & KH-550 & Ethanol & Water \\
\hline Mass fraction (\%) & 17.8 & 63.5 & 18.7 \\
\hline
\end{tabular}

$$
\mathrm{LMC}=\frac{\mathrm{AF}_{5 / 13} \mathrm{C}}{\mathrm{TAC}} \times 100 \%,
$$

where $\mathrm{AF}_{5 / 13} \mathrm{C}$ is the area of the first $5 / 13$ of chromatogram and TAC is the total area beneath chromatogram.

2.4.3. Asphaltene Content Tests. The content of asphaltene at different layers was tested according to the Standard Test Methods of Bitumen and Bituminous Mixtures for Highway Engineering in China (JTG E20-2011). In this work, $\mathrm{n}$-heptane and toluene were used to extract asphaltene. The insoluble was further extracted after the asphalt was extracted with n-heptane, and then the soluble was extracted by toluene to obtain asphaltenes. The asphaltene content was calculated from the weight ratio of asphaltene to asphalt sample.

2.4.4. Contact Angle Test between Emulsified Asphalt and $R A P$. The contact angle measuring instrument, as a commonly used device in the research of surface free energy, is mainly used to measure the wettability of liquid to solid. The adhesion work of the system can be calculated by measuring the contact angle of emulsified asphalt on the surface of the mineral. The JGW-360BL contact angle measuring instrument was adopted in this work, which mainly includes four parts: sample test bench, lighting equipment, microsyringe, and image analysis software.

The contact angle test process is as follows: the L1 layer asphalt was heated and melted and then adhered on a $76 \times 26 \mathrm{~mm}$ glass slide to form an asphalt film. After cooling, the slide was immersed in distilled water, $\mathrm{S}-\mathrm{Si}, \mathrm{S}-\mathrm{Ca}$, and $\mathrm{S}$-Si-Ca, respectively. In order to prevent the precipitation of solid particles during the soaking process, the slurry needed to be constantly stirred. The temperature of the solution was controlled at $30^{\circ} \mathrm{C}$ and the soaking time was $30 \mathrm{~min}$. After the

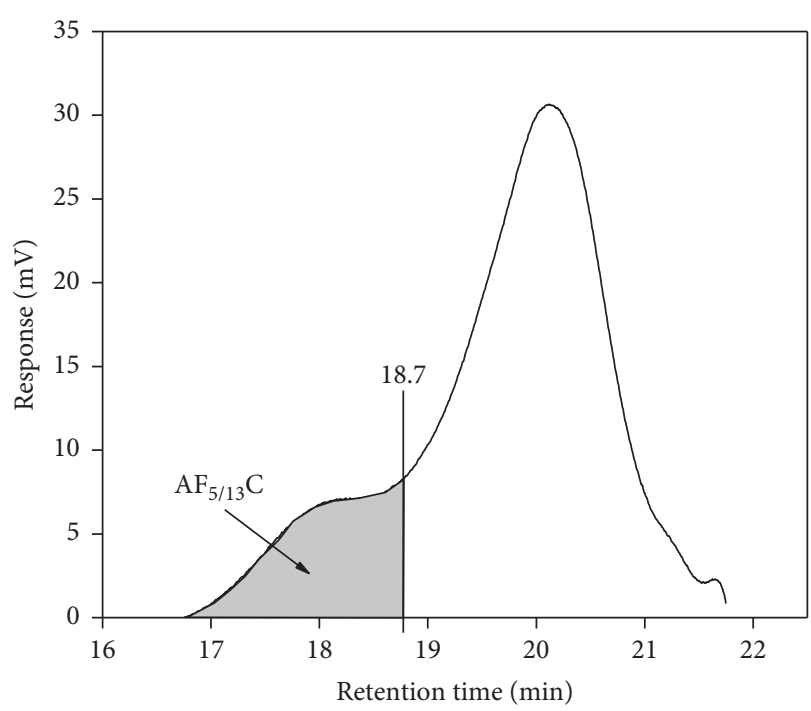

FIGURE 4: GPC analysis diagram of asphalt.

soaking, asphalt sample was left to dry. Finally, the contact angle between the treated sample and emulsified asphalt was tested.

2.4.5. Adhesion Test between Emulsified Asphalt and RAP. The improved boiling test was used to evaluate the adhesion of emulsified asphalt to RAP in this work according to the Standard Test Methods of Bitumen and Bituminous Mixtures for Highway Engineering in China (JTG E20-2011). Since the adhesion of emulsified asphalt was not as strong as that of hot asphalt, relevant improvements were made referring to the original adhesion test. Some $13.2 \mathrm{~mm}-19 \mathrm{~mm}$ RAP with a shape close to cubic were selected and treated with distilled water, $\mathrm{S}-\mathrm{Si}, \mathrm{S}-\mathrm{Ca}$, and $\mathrm{S}-\mathrm{Si}-\mathrm{Ca}$, respectively (the process is the same as that for asphalt in Section 2.4.3).

After treatment, the sample was rinsed with distilled water and dried naturally. Then, the treated RAP was immersed in emulsified asphalt for $1 \mathrm{~min}$, and after being taken out, RAP was hung at room temperature for $24 \mathrm{~h}$. Then the RAP adhered with emulsified asphalt was placed in a $60^{\circ} \mathrm{C}$ water bath for $3 \mathrm{~min}$, and the area percentage of asphalt peeling from the aggregate surface was carefully observed to determine the adhesion grade. Visual observations were made immediately once the sample boiling process was finished. Examination of the sample was conducted under light and with low magnification in the visual observation of retained coating. Any thin, brownish, translucent areas were to be considered fully coated.

\section{Results and Discussion}

3.1. Physical Properties of Asphalt at Different Layers of RAP. The aging degree of asphalt wrapped in different layers on the surface of RAP is different. In order to study the physical properties of asphalt at different layers, the penetration, softening point, and ductility of asphalt samples were tested. The test results are shown in Figure 5. In Figure 5, the softening point of asphalt gradually decreases, while the 


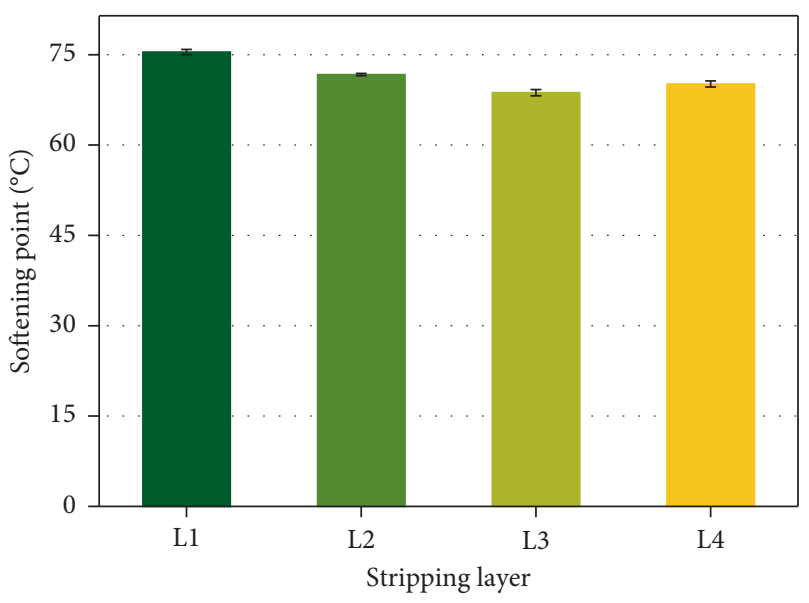

(a)

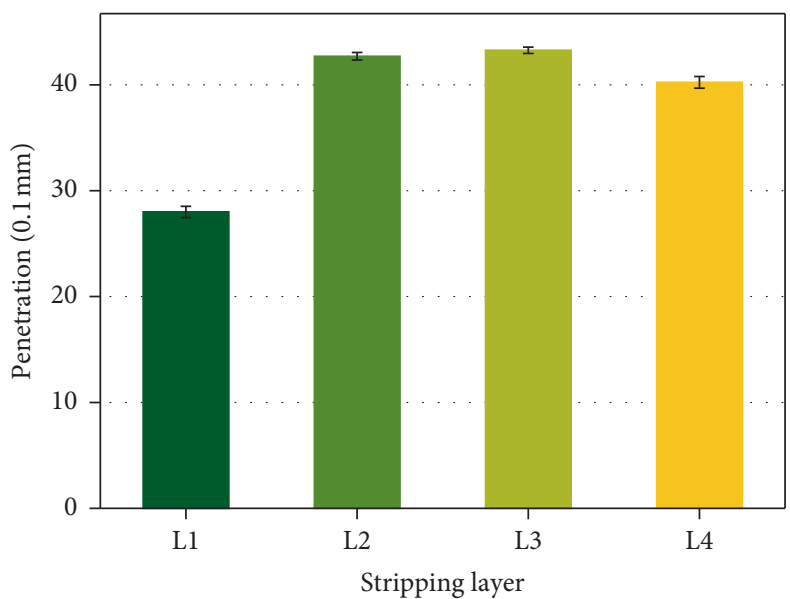

(b)

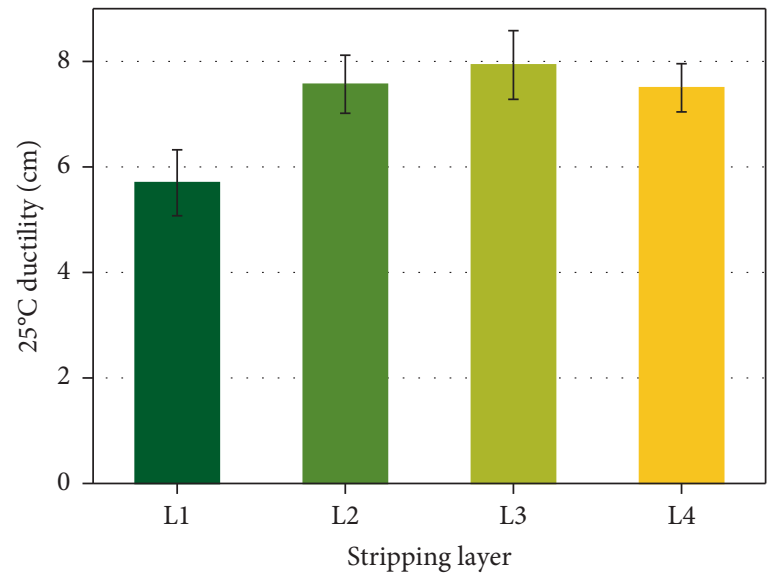

(c)

FIgUre 5: Physical properties of asphalt at different layers: (a) softening point, (b) penetration, and (c) ductility.

penetration and the ductility increase from the outside to the inside of the aggregate. However, the fourth layer of asphalt which is in close contact with aggregate shows an increase in softening point and a decrease in penetration and ductility compared with the third layer of asphalt. It is mainly due to the different aging degree of different layers of asphalt.

The outermost layer asphalt (L1) on the RAP surface suffers from the most severe aging degree due to more contact with the external environment such as air, water, and acid. At the same time, the outer layer of asphalt has a protective effect on the inner asphalt, which can slow down the aging of the inner asphalt. As the aging degree deepens, the dosage of light components in asphalt gradually decreases, and the dosage of heavy components gradually increases. Among the asphalt components, the heavy components determine the temperature sensitivity, hardness, and other characteristics of asphalt. Therefore, the higher the aging degree of asphalt, the harder the asphalt and the worse its physical properties. The main reason for the deterioration of the physical properties of L4 asphalt is that the internal aggregate absorbs the oil content of the asphalt, which reduces the dosage of light components in asphalt and thus increases the dosage of heavy components in asphalt.
3.2. Molecular Weight Analysis of Asphalt at Different Layers. The polymerization reaction can occur between the molecules during aging of asphalt, resulting in the change of molecular weight. GPC can sensitively capture the change of molecular weight and thus reflect the aging degree of asphalt $[26,27]$. Figure 6 shows the GPC spectrum of asphalt at different layers. In Figure 6, the time when the asphalt molecules at different layers begin to flow out is different. The peak positions of asphalt at different layers are also different. The asphalt peak gradually shifts to the left as the aging degree deepens; that is, the proportion of macromolecules in the asphalt sample gradually increases [25].

According to equation (1), the LMC of asphalt at different layers was calculated and the results are shown in Figure 7. In Figure 7, the macromolecule content in L1 is the highest, which can reach $15.7 \%$, as well as followed by $\mathrm{L} 2$ and L4, which are $14.7 \%$ and $14.2 \%$, and the lowest macromolecule content is $\mathrm{L} 3$, which can reach $12.9 \%$. The outermost layer asphalt of RAP suffers from the most aging due to the contact with the external environment. As a result of the absorption of the light components in the asphalt by aggregate, the heavy component dosage of the L4 layer asphalt is increased, so the proportion of macromolecules is 


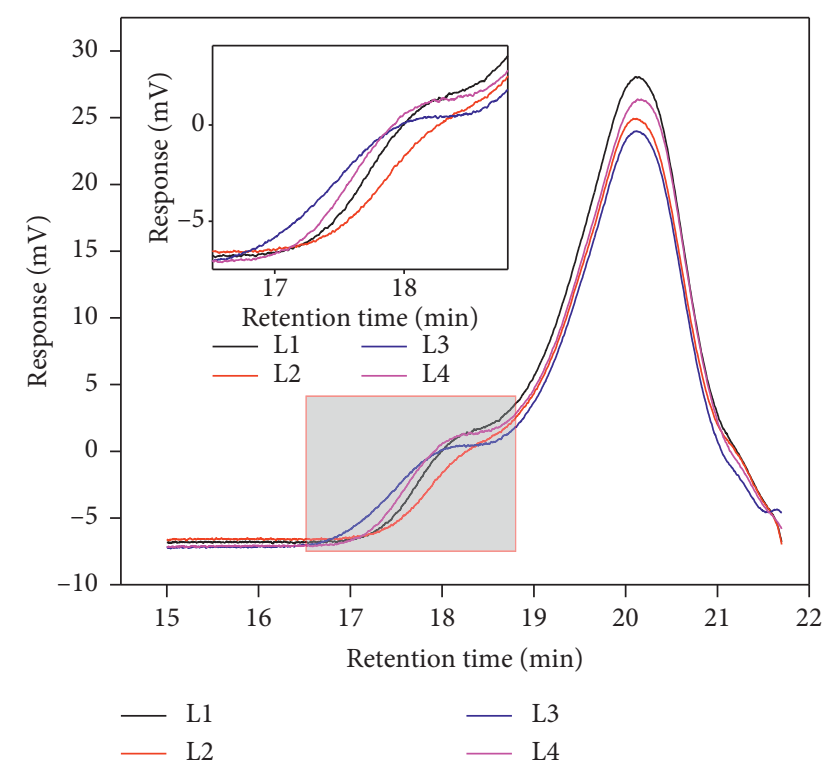

FIGURE 6: GPC curves of asphalt at different layers.

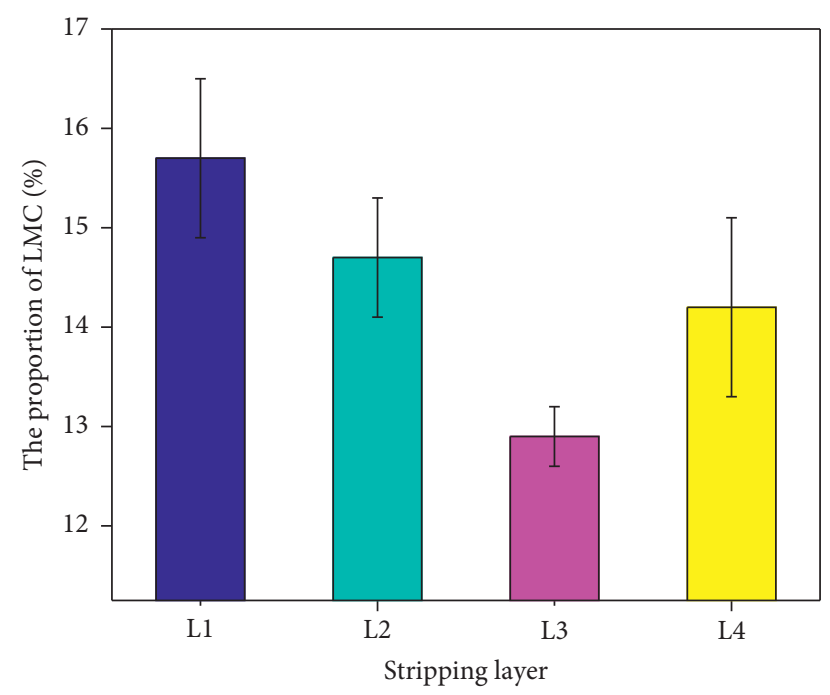

Figure 7: The LMC of asphalt at different layers.

enhanced. The aging of L2 and L3 is lighter due to the less affection by environmental erosion or aggregate absorption, so the proportion of macromolecules is relatively small.

From the physical performance results, the softening point, penetration, and ductility of the L1-L3 layers all maintained a certain law, but abnormalities occurred in the L4 layer. It can attribute to the absorption of lightweight components by the aggregate. This is because the molecular weight of asphalt is closely related to the physical properties of asphalt. Small molecules can promote the sliding of molecular chains. The higher the proportion of small molecules in the asphalt, the easier the molecular chain movement. On the other hand, the higher the proportion of macromolecules, the stronger the entanglement of molecular chains with each other, and the more difficult the molecular chain movement is, and thus the aged asphalt with higher LMC gradually hardens and its physical properties decrease. This can also explain why the physical properties of L4 asphalt have inflection points.

3.3. Change of Asphaltene Content at Different Layers. The chemical composition of asphalt is closely related to its physical properties. The higher the content of asphaltene, the more serious the aging of asphalt and the higher the content of macromolecule in asphalt. The asphaltene was extracted according to the characteristics of asphaltene that can be insoluble in n-heptane. Figure 8 shows the asphaltene content of asphalt peeling from different layers on the RAP surface.

It can be seen from Figure 8 that the asphaltene content in L1 is the highest, indicating the L1 asphalt suffered from the most serious aging. Under the impact of light and heat, the light components of asphalt gradually change to asphaltene, resulting in the highest asphaltene content in the L1. Moreover, the aging degree of inner asphalt is smaller due to the most external asphalt coating. The content of asphaltene kept a decrease from L1 to L3. However, L4 asphaltene content increased compared with L3, which can be mainly due to the mineral absorption of light components rather than the aging condition. L4 is far from the external atmosphere, so the possibility of L4 being affected by the external environment and aging is much lower than the other three layers.

3.4. Effects of RAP Modification on Contact Angle. In contrast to ordinary aggregate, the surface of RAP has different adhesion characteristics with emulsified asphalt due to the existence of asphalt aging film. The surface energy between asphalt and RAP is directly related to the adhesion characteristics between them from the perspective of thermodynamics, so the free energy theory can be used to evaluate the adhesion performance of RAP and predict the adhesion force between modified RAP and emulsified asphalt [10].

When liquid comes in contact with solid, the liquid can have a wetting or adsorption effect on the solid surface due to the difference in surface energy between them. The contact of emulsified asphalt with RAP can be equivalent to the wetting process of emulsified asphalt and RAP. The contact angle between emulsified asphalt and RAP can change as the surface energy of the two changes. According to Young's equation, as shown in equation (2), the adhesion force between the liquid and the solid can be calculated as long as the surface tension $\gamma_{l}$ of the liquid and the contact angle $\theta$ between them are measured. The surface tension of the same test liquid is the same. Therefore, the smaller the contact angle, the greater the adhesion force between the solid and the liquid.

$$
W_{a}=\gamma_{l}(\cos \theta+1),
$$

where $W_{a}$ is the adhesion of the two substances, $\gamma_{l}$ is the surface tension of the liquid, and $\theta$ is the contact angle between the liquid and the solid. 


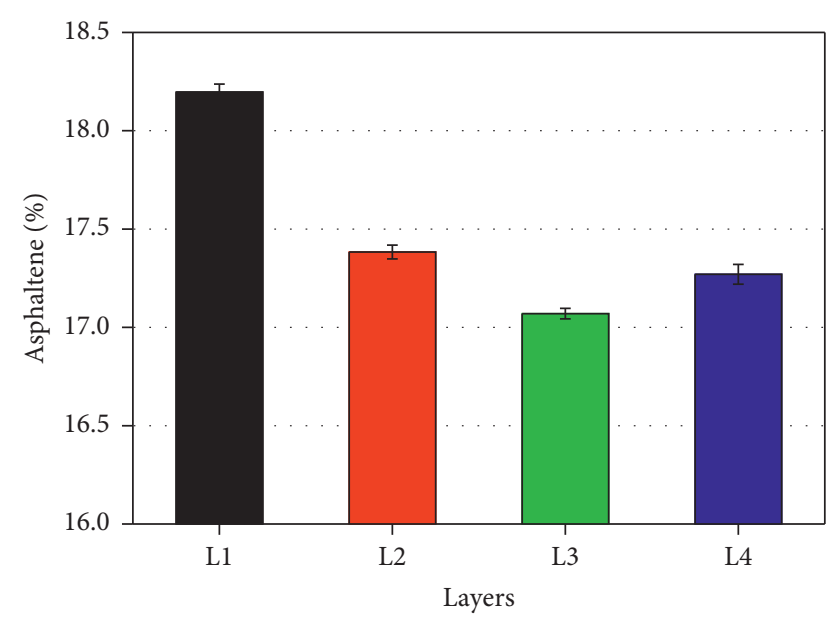

Figure 8: The asphaltene dosage of asphalt at different layers.

Figure 9 shows the effect of SCA dosage on the modification effect of S-Ca. The contact angle between emulsified asphalt and RAP gradually decreased with the increase of SCA dosage (0-3\%), indicating that the effect of SCA on the surface modification effect of asphalt has gradually been improved. However, the contact angle of emulsified asphalt to RAP gradually increases when the dosage of SCA exceeds a certain proportion (3\%). This is because suitable SCA can adhere $\mathrm{Ca}(\mathrm{OH})_{2}$ solid particles to asphalt surface. However, the solid particles of $\mathrm{Ca}(\mathrm{OH})_{2}$ can be completely covered by the SCA when the dosage of SCA exceeds a certain limit. This is not conducive to the adsorption of $\mathrm{Ca}(\mathrm{OH})_{2}$ solid particles on emulsified asphalt particles, so the contact angle gradually increases. The 3\% SCA dosage was selected as a precondition to the formulation of the three modifiers, S-Si, $\mathrm{S}-\mathrm{Si}-\mathrm{Ca}$, and S-Ca. After the asphalt was treated by the three modifiers, the contact angle was tested.

The contact angle test results after different modification treatments are shown in Figure 10. In Figure 10, the contact angle between aging asphalt and emulsified asphalt is $57.8^{\circ}$. The contact angle with emulsified asphalt particles after the $\mathrm{S}$-Si treatment did not decrease, but increased by $1.7^{\circ}$. However, the contact angles of emulsified asphalt particles on asphalt surface after S-Ca and S-Si-Ca treatment decreased by $3.5^{\circ}$ and $10.5^{\circ}$, respectively. It shows that the adhesion between RAP and emulsified asphalt is improved after S-Ca and S-Si-Ca treatment. After the S-Ca was modified with SCA, the contact angle between emulsified asphalt and RAP is evidently decreased, which indicates that the adhesion between RAP treated with S-Si-Ca and emulsified asphalt is the highest.

3.5. Adhesion between Emulsified Asphalt and Modified RAP. The adhesion of RAP treated by different modifiers to emulsified asphalt is shown in Figure 11. It can be seen from Figure 11 that the stripping amount of untreated RAP surface asphalt after boiling test is the most, and the stripping amount of RAP surface asphalt after S-Si and S-Ca treatment decreases. However, the overall stripping area is more than 30\%; therefore, the adhesion grade was

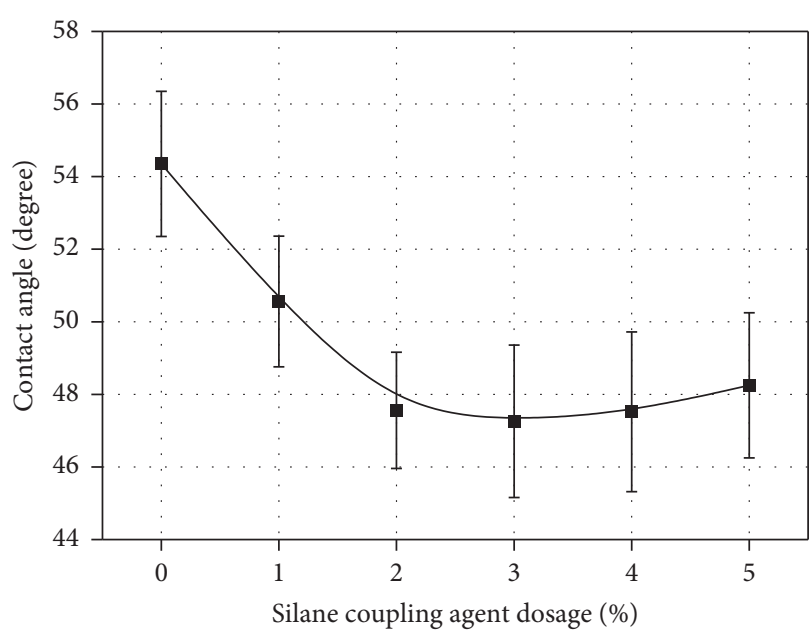

FIGURE 9: Effect of SCA dosage on the contact angle.

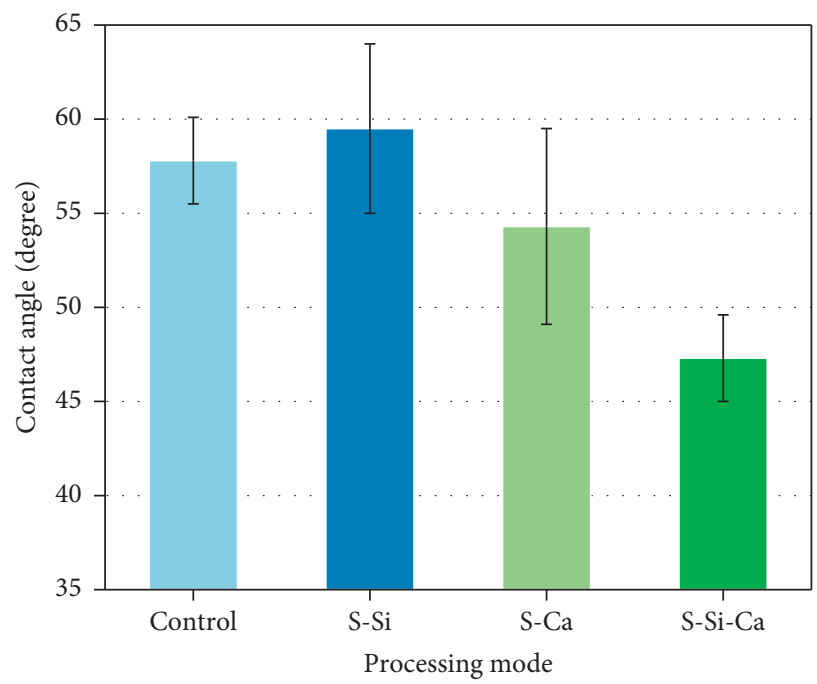

FIGURE 10: Contact angles between emulsified asphalt and RAP with different treatments.

determined as grade II. However, after S-Si-Ca treatment of RAP, the stripping amount of RAP surface asphalt significantly reduced, and the total stripping amount is between $10 \%$ and $30 \%$, so the adhesion grade was determined as grade III.

The adhesion of RAP to emulsified asphalt is shown in Table 7. In Table 7, the adhesion grade of emulsified asphalt and RAP without treatment and treated with S-Si and S-Ca keeps the same. However, the adhesion grade of emulsified asphalt and RAP is improved to grade III after treated with $\mathrm{S}$-Si-Ca. The main reason is that the SCA and $\mathrm{Ca}(\mathrm{OH})_{2}$ can improve the wetting ability of emulsified asphalt to RAP, so the adhesion of RAP and emulsified asphalt is significantly improved.

3.6. Mechanism of Adhesion Changes between Emulsified Asphalt and RAP. The effect diagram of the modifier on RAP is shown in Figure 12. In the cold mixing process of asphalt, 


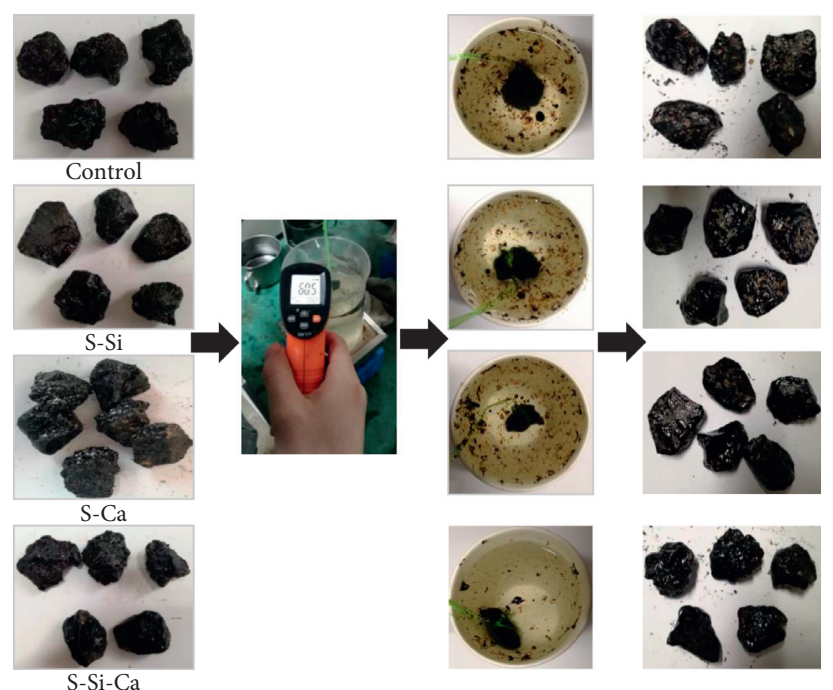

Figure 11: The adhesion grade test for emulsified asphalt and RAP.

TABLE 7: Adhesion results of emulsified asphalt and RAP.

\begin{tabular}{lrr}
\hline Treated methods & RAP surface condition & Adhesion grade \\
\hline Control & Most of the asphalt film is desorbed, and the percentage of stripping area is more than $30 \%$ & II \\
S-Si & Asphalt film is obviously desorbed, but the percentage of stripping area is less than $30 \%$ & II \\
S-Ca & III & III \\
S-Si-Ca &
\end{tabular}

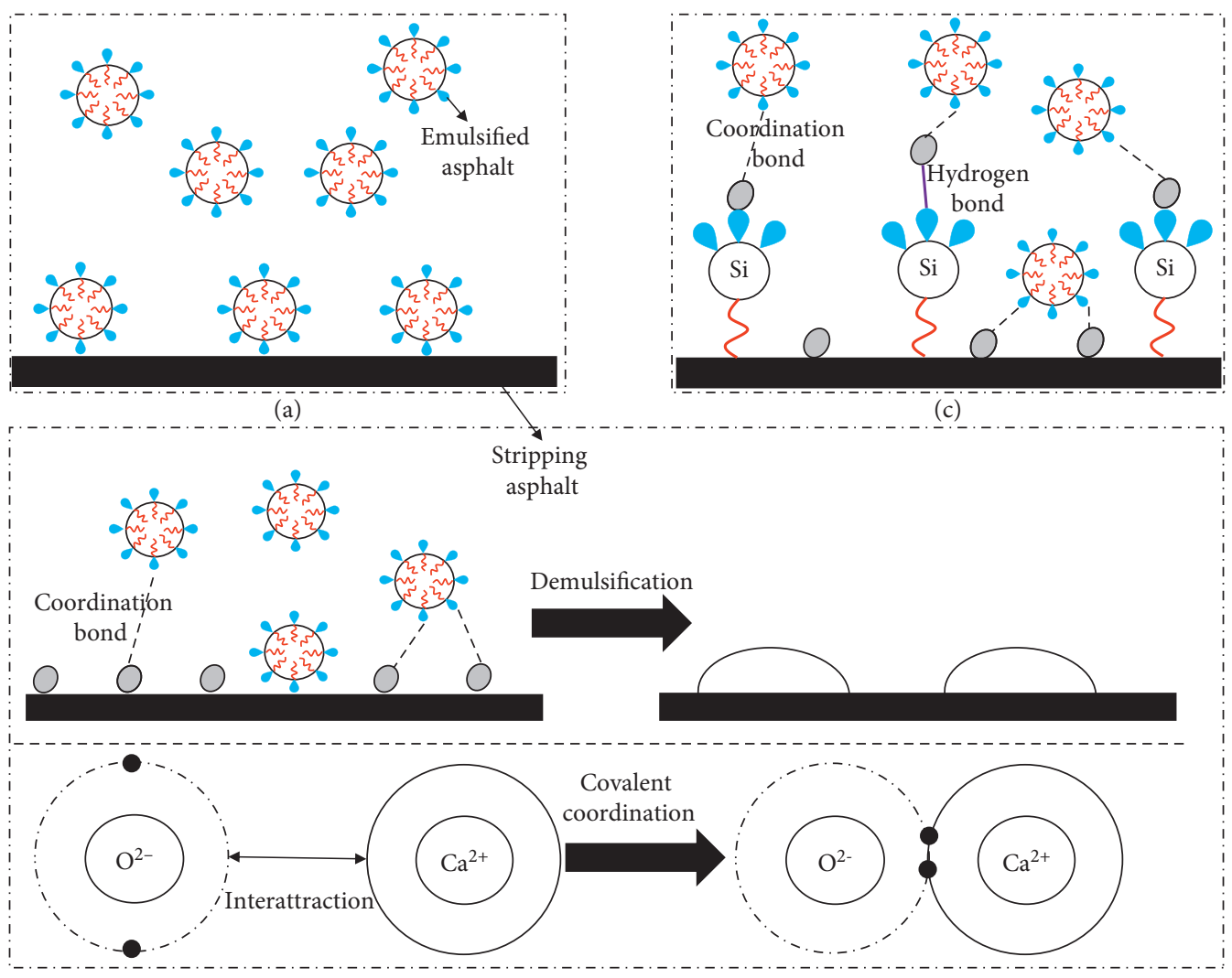

(b)
Hydrophilic group
$\bigcirc \mathrm{Ca}(\mathrm{OH})_{2}$
$\sim$ Lipophilic group
- Electron

FIgURE 12: Diagram of adhesion between emulsified asphalt and RAP: (a) control, (b) S-Ca, and (c) S-Si-Ca. 
emulsifier molecules can be adsorbed with inorganic materials such as aggregate and cement, which can result in the demulsification of emulsified asphalt. The droplets of asphalt would demulsificate and form asphalt film on the surface of aggregate. However, as shown in Figure 12(a), the hydrophilic groups on the surface of emulsified asphalt have poor compatibility with the lipophilic group on RAP surface asphalt, which hinders emulsified asphalt particles to spread on the asphalt surface.

As can be seen from Figure 12(b), S-Ca is used as an intermediate in this paper to tightly connect the aged asphalt on the RAP surface with emulsified asphalt. At the interface between aged asphalt and $\mathrm{Ca}(\mathrm{OH})_{2}$, the key point is the acidbase reaction. $\mathrm{Ca}(\mathrm{OH})_{2}$ has strong alkalinity and can react with the acidic substances in the asphalt to form calcium salts. These organic calcium salts have strong polarity and can form stronger bonds than organic acids or anhydrides [28]. Moreover, the asphalt containing calcium ion on the RAP surface can promote the adsorption and demulsification of emulsified asphalt and can also enhance the adhesion between emulsified asphalt and RAP. Calcium exists in S-Ca in the form of $\mathrm{Ca}^{2+}$. The arrangement of extranuclear electrons of calcium atom is $1 s^{2} 2 s^{2} 2 p^{6} 3 s^{2} 3 p^{6} 4 s^{2}$, and that of $\mathrm{Ca}^{2+}$ is $1 s^{2} 2 s^{2} 2 p^{6} 3 s^{2} 3 p^{6}$. It can be seen from the arrangement of extranuclear electrons that $\mathrm{Ca}^{2+}$ loses two electrons in the 4 s orbit, so $\mathrm{Ca}^{2+}$ has an empty orbit without electrons. According to the formation conditions of covalent coordination bond, the 4 s orbital of $\mathrm{Ca}^{2+}$ will receive two lone electrons contained in oxygen atom of emulsifier to form covalent coordination bond when emulsified asphalt is in contact with S-Ca. Therefore, the adhesion between aged asphalt modified by S-Ca and emulsified asphalt increases.

Due to the aging behavior of asphalt, the acidity of the RAP surface asphalt can be reduced, for the acidic substances in the asphalt can be decreased by environmental erosion [29], which can weaken the reaction between aged asphalt and S-Ca and hinder the formation of calcium salts and thus can influence the effect of the S-Ca modification. The adhesion between emulsified asphalt and RAP was further increased after RAP was treated by S-Si-Ca. On the one hand, as shown in Figure 12(c), the hydrophilic group of SCA can adsorb and form hydrogen bond with inorganic particles $\mathrm{Ca}(\mathrm{OH})_{2}$. On the other hand, the lipophilic group of SCA can react with organic substance on the surface of asphalt to form a chemical bond, which can well adsorb on the asphalt surface to form the structure of aged asphaltSCA-Ca $(\mathrm{OH})_{2}$-emulsified asphalt so that aged asphalt and emulsified asphalt can be firmly combined.

\section{Conclusions}

In this work, a self-designed RAP delamination and stripping device was applied to separate the asphalt on the RAP surface. The properties of asphalt at different stripping layers, such as penetration, softening point, $25^{\circ} \mathrm{C}$ ductility, and molecular weight were studied. In addition, different modification methods were used to modify the asphalt on the RAP surface and the modification effect was determined through contact angle and boiling test. Finally, the mechanism of different modification methods was analyzed. The following conclusions are drawn:

(a) The asphalt on the RAP surface was successfully stripped into four layers through the self-designed RAP delaminating and stripping device. The asphalt wrapped around the surface of the RAP showed a tendency to be gradually hardened from outside to inside. However, asphalt at the innermost layer (L4) being close contact with aggregate is slightly harder than that at L3 due to the fact that the light components are absorbed by the aggregate.

(b) The proportion of macromolecules in L1 layer asphalt is the highest, which is followed by L4, L2, and L3 layers. This further proves that the aging degree of asphalt at different stripping layers is different, which maintains the same as the results of physical properties. In general, the aging degree of asphalt on the RAP surface is $\mathrm{L} 1>\mathrm{L} 4>\mathrm{L} 2>\mathrm{L} 3$. In addition, the change rule of asphaltene is consistent with that of macromolecules.

(c) The modification effect is improved at first but then worsened with the increase of the dosage of SCA. The reasonable dosage of SCA is determined as $3.0 \%$ in $\mathrm{Ca}(\mathrm{OH})_{2}$ powder mass. The modification effect of the three different treatment methods gradually worsens from S-Si-Ca, S-Ca to S-Si.

(d) The reason behind the best modification effect for $\mathrm{S}$-Si-Ca RAP is that the SCA can react with organic substance on the asphalt surface to produce chemical bonds. Meanwhile, SCA can bring $\mathrm{Ca}(\mathrm{OH})_{2}$ particles to the asphalt surface to form asphalt-SCA-Ca $(\mathrm{OH})_{2}$ structure.

\section{Data Availability}

The data used to support the findings of this study are included within the article.

\section{Conflicts of Interest}

The authors declare that they have no conflicts of interest.

\section{Acknowledgments}

This work was supported by the National Natural Science Foundation of China (no. 51978067), Science and Technology Development Project of Xinjiang Production and Construction Corps (no. 2019AB013), the State Key Laboratory of High Performance Civil Engineering Materials (no. 2018CEM010), Henan Transportation Science and Technology Plan Project (no. 2019J1), and the Fundamental Research Funds for the Central Universities of China (no. 300102310501).

\section{References}

[1] A. Sultan Saud and Z. Guo, "Evaluating the performance of sustainable perpetual pavements using recycled asphalt pavement in China," International Journal of Transportation Science and Technology, vol. 5, no. 3, pp. 200-209, 2017. 
[2] J. Ouyang, J. Zhao, and Y. Tan, "Modeling mechanical properties of cement asphalt emulsion mortar with different asphalt to cement ratios and temperatures," Journal of $\mathrm{Ma}$ terials in Civil Engineering, vol. 30, no. 10, Article ID 04018263, 2018.

[3] W. Fedrigo, W. P. Núñez, T. R. Kleinert, M. F. Matuella, and J. A. P. Ceratti, "Strength, shrinkage, erodibility and capillary flow characteristics of cement-treated recycled pavement materials," International Journal of Pavement Research and Technology, vol. 10, no. 5, pp. 393-402, 2017.

[4] H. Majidifard, N. Tabatabaee, and W. Buttlar, "Investigating short-term and long-term binder performance of high-RAP mixtures containing waste cooking oil," Journal of Traffic and Transportation Engineering (English Edition), vol. 6, no. 4, pp. 396-406, 2019.

[5] M. Ali, Z. Hassan, M. R. M. Aliha, and Y. Saghafi, "Laboratory study of the effect of oil-based recycling agents on high RAP asphalt mixtures," International Journal of Pavement Engineering, vol. 224, pp. 89-98, 2019.

[6] H. Ziari, A. Moniri, and N. Norouzi, "The effect of nanoclay as bitumen modifier on rutting performance of asphalt mixtures containing high content of rejuvenated reclaimed asphalt pavement," Petroleum Science And Technology, vol. 37, no. 17, pp. 1946-1951, 2019.

[7] Y. Xu, Z. Chou, Y. Li, J. Ji, and S.-F Xu, "Effect of blending degree between virgin and aged binder on pavement performance of recycled asphalt mixture with high RAP content," Advances in Materials Science and Engineering, vol. 2019, p. 5741642, 2019.

[8] Y. Ding, B. Huang, and X. Shu, "Blending efficiency evaluation of plant asphalt mixtures using fluorescence microscopy," Construction and Building Materials, vol. 161, no. 10, pp. 461-467, 2018.

[9] B. Mohamadtaqi and H. Ali, "Rheological and chemical characteristics of asphalt binders recycled using different recycling agents," Construction and Building Materials, vol. 228, pp. 1-14, 2019.

[10] Pi YuHui, Li Yan, Y.X. Pi, X.Y. Tan, and M.M. He, "Wetting model of asphalt on the aggregate surface and its effect factors," Advances in Materials Science and Engineering, vol. 2019, p. 4126464, 2019.

[11] Z. Wang, D. Nan, X. Wang, J. Zhang, and H. Guo, "Laboratory investigation on effects of microwave heating on early strength of cement bitumen emulsion mixture," Construction and Building Materials, vol. 236, pp. 1-13, 2020.

[12] W. Yang, J. Ouyang, M. Yan, T. Tang, J. Chen, and B. Han, "Effect of superplasticizer and wetting agent on volumetric and mechanical properties of cold recycled mixture with asphalt emulsion," Advances in Materials Science and Engineering, vol. 2020, pp. 6251653-11, 2020.

[13] Li Jin, M. Yu, X. Cui, and W. Wang, "Properties and components of recycled engine oil bottom rejuvenated asphalt and its grey relationship analysis," Advances in $\mathrm{Ma}$ terials Science and Engineering, vol. 2019, Article ID 2462487, 11 pages, 2019.

[14] M. Yu, Li Jin, X. Cui, D. Guo, and X. Li, “Antiageing performance evaluation of recycled engine oil bottom used in asphalt rejuvenation," Advances in Materials Science and Engineering, vol. 2019, Article ID 2947170, 8 pages, 2019.

[15] F. Haghshenas Hamzeh, R. Rea, B. Dale, D. F. Haghshenas, R. Gerald, and Z. Martins, "Asphalt binder laboratory shortterm aging: effective parameters and new protocol for testing," Journal of Materials in Civil Engineering, vol. 32, no. 1, Article ID 04019327, 2020.
[16] X. Li, J. Shen, P. Shi, and H. Zhu, "Nonlinear modeling of nanoscaled properties of asphalt binders recovered from weathered asphalt mixtures," Journal of Materials in Civil Engineering, vol. 32, no. 1, Article ID 04019340, 2020.

[17] D. Zhang, B. Birgisson, X. Luo, and I. Onifade, "A new longterm aging model for asphalt pavements using morphologykinetics based approach," Construction and Building Materials, vol. 229, Article ID 117032, 2019.

[18] E. Kim Robin, S. Kang, F. Spencer Billie, Ozer Hasan, and L. Al-Qadi Imad, "Stochastic analysis of energy dissipation of a half-car model on nondeformable rough pavement," Journal of Transportation Engineering Part B Pavements, vol. 143, no. 4, Article ID 04017016, 2017.

[19] D. Wang, H. Zhang, and H. Zhang, "Shearing property and permanent deformation prediction model of cold recycled mixture with emulsified asphalt," Journal of Jiangsu University. Natural Science Edition, vol. 38, no. 2, pp. 204-210, 2017.

[20] Z. Wang, X. Shu, T. Rutherford, B. Huang, and D. Clarke, "Effects of asphalt emulsion on properties of fresh cement emulsified asphalt mortar," Construction and Building Materials, vol. 75, pp. 25-30, 2015.

[21] G. Xu and H. Wang, "Study of cohesion and adhesion properties of asphalt concrete with molecular dynamics simulation," Computational Materials Science, vol. 112, pp. 161-169, 2016.

[22] X. Lv, W. Fan, J. Wang et al., "Study on adhesion of asphalt using AFM tip modified with mineral particles," Construction and Building Materials, vol. 207, pp. 422-430, 2019.

[23] O. Xu, Z. Wang, and R. Wang, "Effects of aggregate gradations and binder contents on engineering properties of cement emulsified asphalt mixtures," Construction \& Building Materials, vol. 135, pp. 632-640, 2016.

[24] G. Shashibhushan and D. Singh, "Effects of bio-oil on performance characteristics of base and recycled asphalt pavement binders," Construction and Building Materials, vol. 227, pp. 1-13, 2019.

[25] X. Wang, H. Guo, B. Yang, X. Chang, C. Wan, and Z. Wang, "Aging characteristics of bitumen from different bituminous pavement structures in service," Materials, vol. 12, no. 3, p. 530, 2019.

[26] X. Xie, S. Tong, Y. Ding, H. Liu, and L. Liang, "Effect of the amount of mineral powder on the ultraviolet aging properties of asphalt," Advances in Materials Science and Engineering, vol. 2016, Article ID 5207391, 9 pages, 2016.

[27] M. Zhang, P. Hao, S. Dong, Y. Li, and G. Yuan, "Asphalt binder micro-characterization and testing approaches: a review," Measurement, vol. 151, p. 107255, 2020.

[28] S. Han, S. Dong, M. Liu, X. Han, and Y. Liu, "Study on improvement of asphalt adhesion by hydrated lime based on surface free energy method," Construction and Building Materials, vol. 227, p. 116794, 2019.

[29] X. Zhang, Influence of Aqueous Solution on Properties of Asphalt and Asphalt Concrete, Wuhan University of Technology, Wuhan, China, 2018. 